\title{
Martin Jay
}

\section{Foto-urealisme}

Kameraets bidrag til okularcentrismens krise

Lad mig begynde med at bede Dem om uden videre at godtage en forudsætning, som jeg ikke vil få tid til at forsvare eller blot udarbejde her, men som jeg har diskuteret andetsteds og håber at bevise $\mathrm{i}$ fuldt omfang inden for rammerne af den bog, jeg skriver på nu. ${ }^{1}$. Forudsætningen består $\mathrm{i}$ den hidtil ubemærkede eksistens af en gennemtrængende og dybt rodfæstet forkastelse hos et bredt udsnit af det 20 . århundredes franske intellektuelle af den vestlige kulturs okularcentristiske ensidighed. Mens vore dominerende filosofiske, videnskabelige og æstetiske traditioner almindeligvis har hyldet »synets adelsmærke $\ll^{2}$, er utallige franske tænkere $\mathrm{i}$ det mindste siden Bergson i stigende grad begyndt at mistro dets hegemoniske rolle i moderne epistemologi, æstetik og endog i det sociale liv. Det begyndte med en mistanke til rækkevidden af den moderne æras dominerende synsmåde [scopic regime], der kombinerede Albertiansk perspektivisme med en Cartesiansk tiltro til bevidsthedens øjes monokulære blik på »klare og tydelige ideer«; derfra bredte deres kritik sig ofte til at omfatte enhver udgave af det visuelles forrang, hvad enten den beroede på spekulation, observation eller åbenbaringens lys.

Et righoldigt eksempelmateriale fra så forskelligartede tænkere som Bataille og Sartre, Blanchot og Foucault, Metz og Irigaray, Levinas og Lyotard, Lacan og Derrida kunne fremføres som forsvar for disse generaliseringer, som jeg må bede Dem godtage uden bevis. Hellere end at bruge al min tid på at fremlægge et sådant, foretrækker jeg i stedet at hellige den, hvad jeg tror meget vel kan være en del af forklaringen på denne vidt udbredte bortvending fra okularcentrismen. Jeg understreger denne forklarings begrænsede omfang, for der er givetvis andre overvejelser, der også må fremføres, f.eks. nybruddene i det 19. århundredes forstålse af optikkens fysiologiske grundlag, den moderne bys forandring $i$ det visuelle landskab og tilmed indtrykket af første verdenskrig.

Den omstændighed, jeg ønsker at udforske i dette foredrag, er imidlertid ikke blot et centralt element i sagen; den er også særdeles fas- 
cinerende, fordi dens årsagsbetingede forbindelse med nedrakningen af synet intuitivt vil synes så paradoksal. Jeg ønsker at argumentere for, at den mest bemærkelsesværdige udvidelse af den menneskelige synsevne, i det mindste siden det 17. århundredes mikroskop og teleskop, i sidste instans bidrog til at underminere tilliden til selve den sans, hvis magt den så stærkt forøgede. Sagen er, at opfindelsen af kameraet, som så ofte har fået æren for at skabe menneskelige omgivelser gennemtrængt af billeder, en livsverden med hyper-visuel stimulans, også fremmede indpodningen af en skarp reaktion på den kritiske diskurs' niveau mod netop dette resultat. Denne reaktion nærede på sin side den udbredte stillen spørgmål ved okularcentrismen, hvis komplicerede følger jeg håber at udforske andetsteds.

En formidabel litteratur er blevet helliget dokumentationen af fotografiets udvikling og historie, særlig i Frankrig; ${ }^{3}$ jeg skal kun forsøge mig med et hurtigt resumé her. Da Joseph-Nicéphore Niépce og Isadore Niépce, Louis-Jacques Mandé Daguerre og William Henry Fox Talbots opfindelser blev offenligt kendt - de forbedrede i 1830'erne mere eller mindre samtidigt metoder til en permanent fastholdelse af billeder ${ }^{4}$ - var reaktionen i Frankrig og andre steder hurtig og kraftig. Gazette de France rapporterede d. 6.januar 1839: »Denne opfindelse har det fantastiske over sig. Den kuldkaster alle videnskabelige teorier om lys og optik, og den vil revolutionere tegnekunsten. $\aleph^{5}$ Opildnet af den fremtrædende astronom og republikansk medlem af deputeretkammeret, Francois Aragon, tildelte den franske regering Daguerre og Isadore Niépce (hans far var død i $1833)^{6}$ pension til gengæld for, at de opgav deres krav på private patenter. Fotografiets teknik, der blev officielt præsenteret ved et møde i videnskabsakademiet d.19. august 1839, var således fra første færd offentligt tilgængelig.

Den almindelige reaktion på det nye optiske mirakel var overvældende positiv; i 1840'erne skabte det en såkaldt »Daguerreotypimani ${ }^{7}$. Men mellem intellektuelle dukkede snart tre problemer op, som fortsat skaber debat selv i dag. Det første vedrørte forholdet mellem fotografier og optisk sandhed eller illusion. Det andet indførte det irriterende spørgsmål: er fotografi kunst? Det fulgtes naturligt af spørgsmålet: hvilken indflydelse har fotografiet på maleriet og vice versa? Og det tredje rettede sig mod den nye opfindelses virkning i samfundet. Idet de tumlede med disse problemer, hjalp det 19 . århundredes tænkere med til at berede vejen for det 20 . århundredes spørgsmål til synet i dets videre betydning.

Det banale syn på fotografiet har lige fra begyndelsen, da realismens reaktion mod romantikken var på sit højeste, været, at det fastholder et 
moment af virkelighed, som den faktisk forekom. ${ }^{8}$ Daguerre's kamera blev straks kaldt et »spejl« for verden, en metafor der til i dag ofte er blevet gentaget. ${ }^{9}$ Så magtfuld har antagelsen af fotografiets troskab mod den visuelle erfarings sandhed været, at en ikke ringere iagttager end den store filmkritiker André Bazin kunne hævde, at »for første gang er et billede af verden dannet automatisk, uden menneskets kreative indblanding [...] fotografiet påvirker os som et naturfænomen. ${ }^{10} \mathrm{Og}$ selv Roland Barthes argumenterer i sit tidlige essay om »Le message photographique« for, at »billedet ganske vist ikke er virkelighed, men det er i det mindste dens perfekte analogon, og det er præcis denne analogiske fuldkommenhed, der for den almindelige betragtning definerer fotografiet. Således kan man se det fotografiske billedes særlige status: det er et budskab uden en kode. ${ }^{11}$

Den større sammenhæng, som gav fotografiet dets ry, er træffende opsummeret af Noël Burch $\mathrm{i}$ hans diskussion af filmens oprindelse: »Det 19. århundrede blev vidne til en række stadier $\mathrm{i}$ det påtrængende fremskridt for en uhyre forhåbning, der dukkede op som kvintessensen af den borgerlige repræsentationsideologi. Fra Daguerre's Diorama ${ }^{12}$ til Edisons første Kinetofonograf var ethvert stadie i filmens forhistorie tilsigtet af dens iværksættere - og betragtet af dens kommentatorer - som repræsentativ for deres klasse, som endnu et skridt mod virkelighedens 'genskabelse', mod en 'perfekt illusion' af den sanselige verden. ${ }^{13}$ I dette fremskridt blev enhver ny teknisk forbedring som stereoskopet eller farvefilmen betragtet som udbedringen af en mangel i den tidligere evne til at fastholde, hvad der »virkelig« var der.

$P a ̊$ grund af fotografiets evigtvarende gengivelse af det billede, som et camera obscura kunne forme, har det desuden ofte virket, som om det stadfæstede den perspektivistiske synsmåde, som så ofte efter Quattrocento er blevet identificeret med synet selv. ${ }^{14}$ Kameraets $ø j e$, der er lige så monokulart som kighullets, skabte et stivnet, ulegemligt blik på en scene, der er aldeles uden for det selv (en særligt tvingende effekt før for $\varnothing g e l s e n$ af filmhastigheden gjorde ende på den uendelige stille-sidden). Som en »naturens blyant «, for at bruge Fox Talbots berømte vending, leverede kameraet, hvad Ivins ville kalde »billedmæssige udsagn uden syntaks«, direkte billeder af den sande overflade og den sansede verdens tredimensionale dybde. ${ }^{15}$

Sådan var i alt fald den fremherskende mening, da opfindelsen først blev kendt. Nogle iagttagere bekymrede sig over, at de små ansigter på billederne var så virkelige, at de ligesom kiggede igen. ${ }^{16}$ Selv Baudelaire, hvis bidende fjendtlighed mod fotografiets kunstneriske prætentioner vi 
kort skal undersøge, kunne anerkende dets angivelige naturtroskab. ${ }^{17}$ Men hvis fotografiet og dets forbedringer, som det tredimensionale stereoskop der fik en forgrundsstilling i 1860'erne, kunne roses for at tilvejebringe stadig mere pålidelige reproduktioner af den sete verden, begyndte en understrøm af skepsis også at melde sig.

Den mest prominente blandt kameraets opfindere havde, når alt kommer til alt, været en kendt illusionskunstner. Som Aaron Scharf bemærker: »I god tid før sin opdagelse havde Louis-Jacques Mandé Daguerre opnåt en betragtelig berømmelse som maler og opfinder af illusionisteffekter i panoramaer ${ }^{18}$ og fra 1816 som designer af kulisser på Pariseroperaen. Næsten samtidig med at han opfandt dioramaet, den mest populære af alle det tidlige 19. århundredes trompe l'oeil-forlystelser, begyndte Daguerre at eksperimentere med den fotografiske proces. $« 19$ Meget betegnende blev hans berømte dioramaer kaldt »mirakelrum ${ }^{20}$, på grund af den illusionistiske virtuositet de udfoldede. Fordi lysbølgerne indprægedes rent fysisk på kameraets plade, dette materielt grundlæggende led mellem objekt og visuelt tegn som moderne lingvister har kaldt "indeksikalitet ${ }^{21}$, kunne det se ud, som om l'oeil nu ikke blev trompé i Daguerres nye opfindelse. Tvivlen rejste sig dog ikke desto mindre hurtigt.

I midten af 1840 'erne opdagede fotografer, at de kunne retouchere deres fotos eller endog kombinere to til en komposition, en teknik der blev åbenbaret for det målløse franske publikum ved verdensudstillingen i 1855 af en fotograf fra München ved navn Hampfstängel. ${ }^{22}$ Det blev hurtigt normen ved portrættering at hjælpe naturen kosmetisk snarere end blot at registrere den. Interessant nok frenhavede nogle kommentatorer denne evne til at kombinere billeder som et forsvar for det nye mediums artistiske muligheder. ${ }^{23}$ Men det blev også klart, at en vildledende forfalskning af den »sande« lighed med verdens overflade var blevet en varig mulighed. Således blev der $\mathrm{i}$ det såkaldte »ånde-fotografi«, som en amerikansk charlatan, W.H. Mumler, i 1860'erne påduttede et godtroende publikum, registreret nærværende spøgelser optaget med dobbelteksponering. Først da amatørfotografer med deres masseproducerede Kodakapparater i 1880 'erne nåede de samme resultater ved at glemme at rulle filmen frem, var nummeret endegyldigt afsløret.

Endnu større betydning fik den erkendelse, at også uretoucherede fotografier ud fra en vis betragtning kunne siges at viderebringe noget ringere end den perfekte virkelighedsgengivelse enten af objekter i et tredimensionalt rum eller af den menneskelige perception af dem. Så tidligt som i 1853 kommenterede Francis Way begrænsningen $i$, hvad han 
kaldte »heliografen«: »for det første er perspektivets akkuratesse kun relativ: vi har forbedret det, men vi har ikke rettet det aldeles til. For det andet snyder heliografen os med hensyn til forholdet mellem farvetoner. Den afbleger blå farver, skubber grønne og røde over mod sort og kan dårligt fange sarte, hvide skygger. ${ }^{24}$

Skønt det er vanskeligt at rekonstruere de nøjagtige stadier $\mathrm{i}$ den endegyldige desillusionering over for realismens paradigme - eksemplerne Bazin og den tidlige Barthes viser, at den aldrig blev fuldstændig - var dette paradigme ved det 20 . århundredes slutning i praksis tilintetgjort. En hærskare af samtidige kritikere kan bevidne dets forsvinden. Umberto Eco hævder, idet han helt bevidst forkaster Barthes, at »alt det der i billedet stadig forekommer os at være analogt, sammenhængende, ikke-konkret, motiveret, naturligt og derfor 'irrationelt', simpelthen er noget, som det med vort nuværende vidensniveau og operationelle evne endnu ikke er lykkedes os at reducere til det diskrete, det digitale, det rent differentielle $\ll^{25}$, hvorefter han fortsætter med at opregne ti kategorier af koder, som kan anvendes på det fotografiske budskab.

Joel Snyder, der ikke er mindre fjendtlig over for det fotografiske billedes mimetiske fordringer, opsummerer de forskelle, der adskiller billedet fra den menneskelige synserfaring:

»For det første er vort syn ikke formet inden for rektangulære grænser; det er ifølge Aristoteles ubundet. Dernæst, selv om vi lukker det ene øje og anbringer en rektangulær ramme med de samme dimensioner som det oprindelige negativ i den samme afstand fra øjet som linsens brændvidde (det såkaldte afstandspunkt [distance point] i den perspektiviske konstruktion) og så betragter den flade, der er repræsenteret på billedet, ville vi stadig ikke se det samme, som billedet viser. Fotografiet gengiver alt i skarp aftegning fra kant til kant, mens vort syn, fordi vore øjne er gruber, kun er skarpt $i$ »centeret $\ll$. Billedet er monokromatisk, mens flertallet af af os ser $i$ »naturlige « farver (og der er nogle kritikere, der holder fast ved, at billedet ville være mindre realistisk, hvis det var i farver). Endelig, fotografiet viser objekter i skarpt fokus i og på tværs af ethvert plan, fra det nærneste til det fjerneste. Vi ser ikke - fordi vi ikke kan - tingene på den måde. ${ }^{26}$

I følge psykologen James E. Cutting »har øjet hverken lukker eller eksponeringstid, og dog tillader det visuelle system os at se bevægelige objekter tydeligt, hvorimod et fast kamera ville registrere luftslør. $\mathrm{Og}$ dertil kommer, at projektionsfladerne er forskellige ... fotografiet, lærredet 
og tegneblokken er flade; nethinden svarer nærmest til et udsnit af en kugle. ${ }^{27}$ Og Craig Owens tilføjer den videre indvending, at »argumentet der siger, at det fotografiske billedes egenskaber ikke skal udledes af mediets egne karakteristika, men af virkelighedens struktur, der mekanisk er registreret på en lysfølsom overflade, beskriver muligvis fotograferingens tekniske procedure, men det gør ikke rede for fotografiets evne til at frembringe og organisere indre mening. $\ll$

Endskønt det er tvivlsomt, om mange i det 19. århundrede var så klare over forskellene mellem fotografiets og det »naturlige« syns erfaringer som disse forfattere, lod dog ikke enhver sig forføre af realismens tidlige fortaleres påstande. Selv om drømmen om tekniske forbedringer, der skulle føre til sandere og sandere virkelighedsgengivelse, aldrig døde, så syntes hver ny opdagelse at rejse lige så mange spørgsmål, som den havde fået til at forstumme, ${ }^{29}$ en proces der kun blev intensiveret med opfindelsen af filmen.

En tankevækkende fortolkning af opfindelsernes foruroligende effekt retter sig imod deres andel i genopdagelsen af en visuel tradition, der er på kant med den doninerende synsmåde, den som Svetlana Alpers kalder den hollandske »beskrivelseskunst «. Det var måske ikke tilfældigt, at genopdagelsen af Vermer, Hals og deres landsmænd indtraf i 1860'erne kort efter kameraets gennemslag. ${ }^{30}$ Ifølge Alpers »er mange af fotografiets karakteristiske træk - netop de træk der gør det så virkeligt - også almindelige $\mathrm{i}$ den nordlige beskrivelsesmåde: fragmentering, tilfældige rammer, umiddelbarheden som de første udøvere gav udtryk for ved at hævde, at fotografiet har givet naturen magt til at reproducere sig selv direkte uden menneskets hjælp. Hvis vi ønsker historiske fortilfælde for det fotografiske billede, så findes de i den righoldige blanding af syn, viden og afbildning, som trådte frem $\mathrm{i}$ det 17 . århundredes billeder.« 31 Det er derfor Keplers ånd snarere end Descartes' eller Albertis, der svæver over kameraets fødsel. Det døde billlede på nethinden, som han kaldte pictura, fik nu sin mekaniske forankring uden indblanding fra det rationalitetens rum, som den Cartesianske perspektivisme tilføjede. ${ }^{32}$

Hvad enten fotografier passer bedre $i$ den nordlige end $i$ den sydlige billedtradition, så er deres usædvanlige udvidelse af menneskets visuelle erfaring uimodsigelig. Som Benjamin noterede: »fotografiet g $\emptyset r$ for første gang opmærksom på det optisk ubevidste, præcis som psykoanalysen afslører det driftsmæssigt ubevidste. ${ }^{33}$ Lagene i dette ubevidste blev skrællet bort med nye tekniske fremskridt som den kunstige belysning i 1850 'erne og øjebliksbillederne [stop action chronophotography] i 1870 'erne og 1880 'erne. De mest berømte opfindere af det sidste var 
Eadweard Muybridge ${ }^{34}$ i Storbritannien og Etienne Jules Marey i Frankrig. Ved at blotlægge bevægelsesformer, der hidtil havde været usynlige for øjet uden hjælp, bidrog de til at afnaturalisere sædvanlige visuelle erfaringer. Som Aaron Scharf noterer: »Muybridge's fotografier modsagde ikke blot mange af kunstnernes mest nøjagtige og nyeste observationer, også bevægelsens faser hinsides det visuelles tærskel blev blotlagt. Betydningen af termen 'naturtro' mistede sin vægt: hvad der var sandt, kunne man ikke altid se, og det, man kunne se, var ikke altid sandt. ${ }^{35}$

Endnu en foruroligende virkning indtraf, da filmens højere tempo tillod fuldstændig spontane øjeblikke af tilsyneladende flygtighed at blive fanget for altid. Det fik forskellige implikationer. En syntes at være, at livet blev berøvet sin flydende tidslighed ved at få indført en slags visuel rigor mortis, som smedede en lænke mellem kameraet og døden, der stadig er magtfuld i dag. ${ }^{36}$ Skønt de såkaldt »malende« fotografer i det sene 19. århundrede forsøgte at genindføre tiden i deres billeder ved at opbløde fokus, syntes snapshottets skarpkantede brutalitet mere karakteristisk for mediet. En videre implikation, der fulgte af den stivnede flygtighed, var, at idéen om et transcendalt subjekt, der betragtede den samme scene fra evigheden, blev tvivlsom. Som John Berger har mindet om: »Kameraet isolerede øjebliksfremtoninger og ødelagde derved den forestilling, at billeder var tidløse. Eller, for at sige det på en anden måde, kameraet påviste, at begrebet 'tidens gang' var uadskilleligt fra oplevelsen af det synlige (undtagen i malerier). Hvad man så, var afhængigt af, hvor man var hvornår. Hvad man så, står i forhold til ens placering i tid og rum. Det var ikke længere muligt at forestille sig, at alt skulle løbe sammen mod det menneskelige øje som mod uendelighedens forsvindingspunkt. $\ll 37$ Eller for at sige det med Norman Brysons begreber, kameraet hjalp med til at gengive det levende blik sine rettigheder over den stivnede stirren og genindførte samtidig opmærksomheden over for enhver synsevnes deiktiske temporalitet. 38

Det gjorde kameraet imidlertid ved at skabe en temporalitet af ren nutid, i hvilken den narrative tid var ribbet for sin historiske tilbliven. Som Siegfried Kracauer erkendte i 1927, så var fotografiets rumlige betydning en hindring for den sande erindring, hvor meget det end måtte have syntes en hjælp. »I de illustrerede aviser «, skrev han, »er verden blevet fotograferbar nutid, og den fotograferede nutid er som sådan foreviget. Tilsyneladende er den undsluppet døden; i virkeligheden overgiver den sig til den. ${ }^{39}$ Bergsons svar på fotografiet og filmen foregreb netop denne kritik. Så tidligt som i Matière et Mémoire fra 1896 sammenlignede han tidens rumlige karakter, reduktionen af levet durée til et statisk billede, 
med et snapshot. ${ }^{40}$

Opfindelsen af kameraet har altså i det lange løb hjulpet med til at underminere tilliden til øjnenes autoritet og dermed beredt vejen for den kritiske undersøgelse af synet $\mathrm{i}$ det 20 . århundredes franske tænkning. Som filmkritikeren Jean Louis Comolli udtrykker det, "netop som det menneskelige øje bliver så fascineret og belønnet af en hel række synsinstrumenter, som lagger tusinde udsyn for dets blik, mister det dets ældgamle privilegium; den fotografiske maskines mekaniske øje ser nu $i$ dets sted, og i visse henseender med større sikkerhed. Fotografiet fremstår på en gang som øjets triumf og grav.[...] Decentreret, i panik, udleveret til forvirring af al det synliges nye magi, finder det menneskelige øje sig angrebet af en række begrænsninger og tvivl. ${ }^{41}$ Snarere end at bekræfte øjets evne til at gennemskue naturen og samfundet viste fotografiet sig at få den præcis modsatte effekt. Naturens blyant kunne tegne nogle bemærkelsesværdigt unaturlige ting, hvilket det senere eksempel på surrealistisk fotografi demonstrerede så glimrende. ${ }^{42}$ Foto-urealismen skyggede altid for kameraets berømte evne til at frembringe et sandfærdigt billede af virkeligheden.

Den anden store kontrovers, som opfindelsen af kameraet løste op for, vedrørte forholdet mellem fotografi og kunst. ${ }^{43}$ Her var spørgsmålene mangfoldige, og de havde ofte både retslig og teoretisk betydning. ${ }^{44}$ Kunne fotografier virkelig være kunstværker, når kunstnerens hånd tilsyneladende var fraværende ved produktionen? Hvis de var, var traditionel kunstmaling så nu befriet for sin hævdvundne mission med at gengive verden troværdigt på lærredet? Hvis den stadig prøvede at registrere visuel erfaring på en eller anden måde, hvordan påvirkedes denne bestræbelse så af det optisk ubevidste, som fotografiet blotlagde? Og sluttelig, hvilken betydning ville fotografiske reproduktioner af kunstværker $\mathrm{i}$ andre medier få?

I en ofte citeret udtalelse fra den tid, da fotografiet først blev offentligt tilgangeligt, kundgjorde maleren Paul Delaroche: „Fra denne dag er maleriet dødt. ${ }^{45}$ I bogstavelig forstand tog han naturligvis fejl, sk $\emptyset n t$ hærskarer af miniaturemalere mistede deres job. ${ }^{46}$ Men der kan ikke herske tvivl om, at maleriet var grundlæggende ændret af det nye medium. Mange malere, fra ubemærkede portrætmalere til mestre som Delacroix og Ingres, tog ivrigt fotografiet til hjælp i deres arbejde. Nogle var tydeligt påvirkede af, hvad de så. Således har man f.eks. ment, at den hårde opdeling af farverne, som det kunstige lys skaber, har påvirket Manet, og at Corot's proto-impressionisme fra 1840 'erne kan tilskrives inspirationen fra bevægelige objekters slørede billeder på langsomme 
film. ${ }^{48}$ Degas' flygtige billeder af dansere eller heste fanget $\mathrm{i}$ bevægelse er ofte blevet sammenlignet med snapshots, der blev muliggiort med forbedringen af den hurtige film. Den senere indflydelse fra Muybridge og Marey's dissektion af bevægelse er blevet bemærket i det heterogene »opbrudte rum«, der er åbenbart i visse af Manet's billeder og endnu mere udpræget hos Cézanne og Duchamp. ${ }^{49}$ Selv de blændende nøgenmodeller, der stråler ud på tilskueren fra Manet's Dejeuner sur l'herbe og Olympia, er til tider blevet knyttet sammen med det andet kejserdømmes pornografiske portrættering. ${ }^{50}$

Det, der gør alle disse formodede påvirkninger så ironiske, er, at impressionisterne selv almindeligvis hævdede, at de passivt optegnede, hvad de så, fordi de ofte stod i gald til periodens herskende positivistiske ideologi. Endog Cézanne kunne indvende: »Som maler fæstner jeg mig først og fremmest ved det visuelle sanseindtryk. ${ }^{51}$ En endnu større ironi ligger $\mathrm{i}$ det faktum, at den samme naturalistiske påstand om passiv neutralitet fra kameraets tidlige talsmænd var det, der førte til, at det blev forkastet af kunstnere, der var modstandere af ideologien om realistisk mimesis. Så tidligt som tre uger efter, at Daguerre havde henvendt sig til det franske videnskabsakademi, påstod en skribent i Le Charivari, at »betragtet som kunst er M. Daguerre's opfindelse aldeles tåbelig, men betragtet som lysets påvirkning af legemer virkeliggør M. Daguerre's opfindelse et enormt fremskridt. ${ }^{52}$ Daumier beklagede senere, at »fotografiet imiterer alt og udtrykker intet. Det er blindt $i$ åndens verden. ${ }^{53} \mathrm{Og}$ digteren Lamartine kaldte det » denne tilfældige opfindelse som aldrig vil blive kunst, men kun et plagiat af naturen gennem en linse. ${ }^{54}$

Men måske var ingen mere glimrende ringeagtende over for fotografiets kunstneriske prætentioner end Baudelaire, som højlydt beklagede naturalistiske forblindelsers triumf i sin salonanmeldelse fra $1859 .{ }^{55} \mathrm{Sk} \emptyset \mathrm{nt}$ han tilstod den nye teknik videnskabelig og industriel anvendelighed, tordnede han mægtigt mod dens indbrud $\mathrm{i}$ »det uhåndgribeliges og det imaginæres rige. ${ }^{56} \mathrm{Om}$ den vulgære masses begær efter perfekt gengivelse af naturen skrev han: "en hævngerrig Gud har lagt øre til denne sværms bønner. Daguerre var hans Messias [...] Kort efter bøjede tusinde hungrige øjne sig over stereoskopets kighuller, som om det var evighedens loftsvinduer. « ${ }^{57}$. Skønt det er svært at holde Baudelaires foragt for masserne ude fra hans afsmag for deres nye legetøj, er det klart, at han var fuld af mistro over for fotografiets indblanding i kunsten. Denne holdning var så dybt indgroet, at selv senere, da fotografer selvbevidst undgik naturalismen til fordel for en kunstnerisk udsmykning af billedet, 
kunne forfattere som Proust stadig genlyde af Baudelaires mistænksomhed. 58

Den slags beklagelser var fundamentalt fejlplacerede $\mathrm{i}$ en væsentlig henseende: de fantasibårne kunstarter kunne aldrig tilintetgøres af kameraet, fordi, som vi allerede har noteret, dette sidste virkelighedsbillede aldrig selv var ligeud mimetisk eller blot registrerende. Faktisk har kommentatorer som Heinrich Schwarz og Peter Galassi i den senere tid overbevisende demonstreret, at fotografiets forgængere ikke kun var optiske instrumenter som camera obscura, men også visse traditioner i maleriet selv. ${ }^{59}$ Constable's landskaber viser f.eks. en "ny og fundamentalt moderne billedmæssig syntaks med umiddelbare, synoptiske perceptioner og diskontinuerte, uventede former. Det er syntaksen i en kunstart, der hengiver sig til det enkeltstående og tilfældige snarere end til det universelle og bestandige. Det er også fotografiets syntaks. $\ll^{60} \mathrm{Med}$ andre ord, det fotografiske billede kan selv forstås som en station på vejen mellem tidligere ikke-Albertiansk kunst (måske bedst eksemplificeret ved den hollandske »beskrivelseskunst«) og det endegyldige brud med perspektivet i den impressionistiske og post-impressionistiske æra.

Baudelaires foragt for fotografiets korrumperende effekt på kunsten var på et afgørende punkt fejlagtig. Masseproduktionen af malerier og andre kunstværker, der blev påbegyndt af Adolphe Braun i 1862, foregreb, det har mange kritikere noteret, André Malraux's berømte idé med "fantasiernes museum «, $i$ hvilket adgangen til verdenskunsten var blevet almengjort. ${ }^{61}$ Et af resultaterne var, at fotografiske optagelser af eksotiske kulturers kulturgenstande blev et incitament til kunstneriske eksperimenter; billederne supplerede de øvrige udstillede objekter i de etnografiske museer, der blev oprettet $\mathrm{i}$ det 19. århundrede. Opfindelsen af kameraet kan altså få del $\mathrm{i}$ æren for at have hjulpet med at uddanne vestlige øjne til nye æstetiske muligheder. ${ }^{62}$

Fra et andet perspektiv kunne udvidelsen af vestens æstetiske erfarings rækkevidde imidlertid fortolkes som et eksempel på det beherskende antropologiske blik på den »anden «; det er gennemtrængende analyseret af nutidige kritikere som Johannes Fabian og Stephen Tyler. ${ }^{63}$ Selve æstetiseringen af "primitive« kulturgenstande bet $\varnothing$ d, at de blev rykket ud af deres originale kontekst, funktion, ritual o. lign. og kun værdsat i deres abstrakte form. Ingen redegørelse for modernismens forhistorie kan ignorere indflydelsen fra denne opvurdering af primitivismen, som ofte trak på en ældre romantisk tro på det "uskyldige« syns magt, men det er også blevet sværere at ignorere dets tvetydigheder. ${ }^{64}$

Hvis den fotografiske bemægtigelse af det eksotiske »andet« ikke 
umiddelbart foruroligede det 19. århundredes følsomhed, så gjaldt det samme den ny tekniks øvrige sociale konsekvenser, altså i første omgang. Hvad betød, må vi således spørge, denne bemærkelsesværdige udvidelse af vor visuelle erfaring for samfundet? På ét niveau kan fotografen ses som en, der blot fortsæetter en visuel praksis, man allerede havde for hånden. Således har Susan Sontag f.eks. hævdet, at »fotografiet i første omgang bliver sig selv som en forlængelse af middelklasse-flaneurens blik, hvis følsomhed Baudelaire kortlagde så nøjagtigt. Fotografen er en bevæbnet udgave af den ensomme vandrer, sonderende, spankulerende, krydsende det urbane inferno, den voyeuristiske strejfer der opdager byen som et landskab af vellystige yderpunkter. ${ }^{65}$ Ligesom den naturalistiske romanforfatter var fascineret af de »nedre dybders « exotica, kunne fotografen både afsløre og fremkalde de hidtil skjulte afkroges »maleriske« slum. Den ny tekniks påfaldende dokumentationsformåen blev straks forstået i sammenligning med de mere kostbare og besværlige fremgangsmåder, som den erstattede. $\mathrm{Og}$, selvfølgelig, kunne fotografiet også bruges til at udvide reklamens visuelle indflydelse, den var allerede revolutioneret af litografien i løbet af den post-Napoleonske æra.

Mere usædvanlige anvendelsesområder for det nye medium var også mulige. I 1854 opfandt en portræetmaler, A.A.E. Disdéri, det personlige carte de visite ved at formindske et billedes normale størrelse og kopiere negativet billigt et dusin gange. ${ }^{66}$ Opfindelsen, som gjorde Disdéri til en rig mand, før han krakkede under den intense konkurrence fra mange nye atelier'er, havde en klar egalitær virkning. ${ }^{67}$ Alle fra kejseren til det andet kejserdømme filles de joie fra le demi-monde sad for hans kamera. Han foregreb således den kameraets demokratisering under den anden bølge af teknisk udvikling, som amerikaneren George Eastman satte igang med sit Kodak i 1880 'erne.

Men der var andre knap så gunstige konsekvenser af Disdéri's opfindelse. For hvad der begyndte som et privat visitkort, blev snart et offentligt dokument, forhandlet af samlere eller benyttet til autorisationer, pas, efterlysningsplakater og andre statsregulerede former for identifikation og overvågning. Som John Tagg, der skriver fra et Foucault-perspektiv, har peget på, så var det standardiserede billede, der kom ud af det, et tydeligt eksempel på det disciplinerede og normaliserede subjekt, som den moderne magtfulde teknik skabte: »kroppen gjort til objekt; opdelt og studeret; lukket inde $i$ et cellestruktureret rum, hvis arkitektur er kartotekskassens; gjort føjelig og tvunget til at bøje sig for dets sandhed; adskilt $\mathrm{og}$ individueret; underkastet og gjort til undersåt. Når de akkumuleres, danner sådanne billeder en ny forestilling om samfundet «. ${ }^{68}$ Anne 
McCauley finder lige så dystre konsekvenser:

»Middelklassens accept af portrætkortet som et bytteobjekt, et samlerobjekt og arbejdernes efterfølgende overtagelse af skikken, repræsenterer individets snigende transformation til en medgørlig vare. Direkte menneskeligt samvær blev på en måde suppleret med påvirkningen fra et maskinelt frembragt og derfor uafviseligt præcist alter ego, en fabrikeret $»$ anden«. Skabelsen og udbredelsen af visitkortet i løbet af det andet kejserdømme repræsenterer derfor et tidligt skridt hen mod forenklingen af komplekse personligheder til umiddelbart begribelige og koreograferede optrædende, hvis ansigter snarere end handlinger vinder valgene ... $\ll^{69}$

Ikke mindre uheldsvangert var fotografiets anvendelse til politiformål, som for alvor kom i gang som et efterslæt fra Pariserkommunen i $1871 .^{70}$ Kombineret med en problematisk antropologi, der foregav at være i stand til at identificere kriminelle og anarkister ud fra deres fysiognomi, fik teknikken, der blev udviklet i 1880 'erne af Alphonse Bertillon også politiske følger, følger der fortsat skulle bekymre nutidige kommentatorer som John Berger, Susan Sontag og John Tagg. ${ }^{71}$ Ydermere blev den politiske proganda styrket $i$ en befolkning, der endnu for størstedelens vedkommende kun var delvis alfabetiseret, med en dygtig brug af det nye medium, som kom til sin ret i Eugéne Apperts tendentiøst komponerede rekonstruktioner af hændelser under kommunen. ${ }^{72}$ Senere politiske bevægelser, som den der støttede general Boulanger, udvidede den demagogiske brug af fotografisk propaganda.

Endnu en udnyttelse af kamaraets øje var at bruge det til at optage vanviddets såkaldte synlige billede. Efter at det først var forsøgt af Hugh Welch Diamond ved Surrey-asylet i England, kom teknikken til fuld udfoldelse hos Albert Londe på Charcot's klinik Salpêtrière i 1880 'erne. ${ }^{73} \mathrm{Her}$ blev den ældre tradition for afbildning af de sindssyge, der var blevet udviklet af så fremtrædende kunstnere som Le Brun i det 17. århundrede og Géricault i det 19. århundrede, hurtigt overgået, da Marey’s øjebliksbilleder blev brugt til at fryse alle detaljer i galskabens udtryk. ${ }^{74}$ Resultatet blev, hvad en kommentator har kaldt »opfindelsen af hysterien«, den mest fuldkomne visuelle patologi, udspillet af kvinder i Charcot's amfiteaters stadig okularcentristiske verden. Det er meget sigende, at psykoanalysens introduktion i Frankrig, som spillede så afgørende en rolle i videreudviklingen af den anti-okularcentristiske diskurs, jeg ønsker at efterspore, betød en åben forkastelse af Charcot's tro på galskabens 
teatralske repræsentation; »talekuren « behøvede ingen Albert Londe til at afbilde symptomerne på de sår, den håbede at hele.

Mere »normale« emner for det dissekerende fotografiske blik kunne også få deres bevægelser brudt op på måder, der tilskyndede til kontrol. Muybridge's og Marey's opfindelser førte ikke kun til Duchamp's $\mathrm{Nu}$ descendant l'escalier; de hjalp også Frederick Winslow Taylers rationalisering af arbejdsprocessen gennem tids- og bevægelsesstudier. Hans elev, Frank B.Gilbreth, opfandt »cyklografen «, hvor lys blev anbragt på dele af personers kroppe, og ved hjælp af lang eksponeringtid kunne deres bevægelser kortlægges og deres ineffektivitet blive afhjulpet. 75

Kamaraet fik en sidste social anvendelse, der må betragtes som virkeliggørelsen af det principe de survol [oversigtsprincip], der har været højt vurderet af tænkere fra Montesquieu til Flaubert for derefter at blive angrebet af folk som Merleau-Ponty; denne anvendelse udsprang af en af de bedrifter, som det 19.århundredes måske største fotograf, Gaspard Felix Tournachon, kendt som Nadar, udførte. ${ }^{76}$ Nadar var allerede gået under jorden for at optage Paris' katakomber ved kunstigt lys. I 1856 steg han til vejrs $i$ en varmluftsballon for at se byen fra oven. Det første luftfotografi var en sådan succes, at han bestilte en større luftskibskonstruktion, kendt under navnet Le Géant i 1863. Skønt det kostede ham en formue og kun fik blandede følger på grund af tekniske vanskeligheder, markerede det begyndelsen på traditionen med overvågning fra stor højde af menneskets og naturens arbejde, og den kulminerede $i$ de amerikanske astronauters berømmede billeder af jorden fra 1968.

Den franske regering indså metodens umiddelbare nytte og tilbød Nadar 50.000 franc for at fotografere troppebevægelser under konflikten med Italien i 1859. Nadar afslog anmodningen, men under den prøjsiske belejring af Paris i 1870 var han mindre tilbageholdende med at støtte krigshandlingerne. Sammen med brugen af fotografiet til at fremstille kort over landområderne, hvilket man tog fat på i 1859, og fotografers tilknytning til alle hærregimenter, begyndte man på

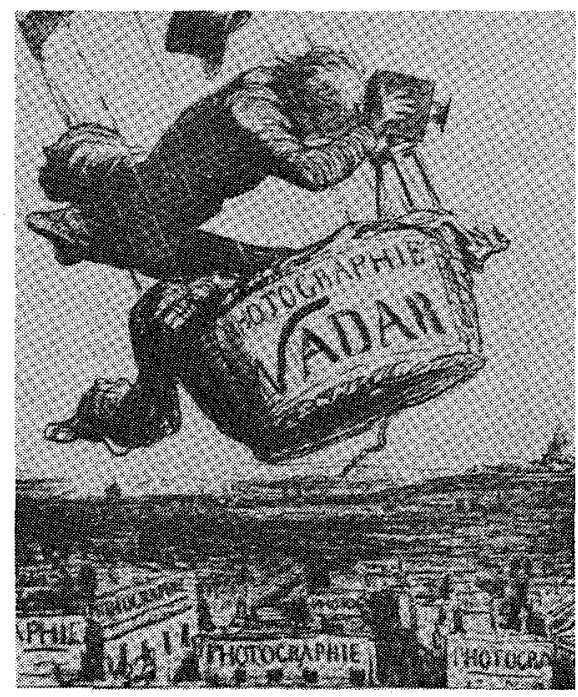


Disdéris opfordring i 1861 at tage luftfotografier, der viste det nye mediums militære betydning.

Nadar $i$ hans højtflyvende ballon var også emnet for en berømmet litografi af Daumier, der blev offentliggjort i 1863 i Etienne Carjat's nyligt oprettede Le Boulevard. Med den humoristiske overskrift »Nadar hæver fotografiet til kunstens højder« viser det fotografen usikkert hængende $\mathrm{i}$ ballonens svajende kurv; hans høje hat fanges af vinden, idet han knipser en by fuld af fotografiatelier'er under sig. Som Heinrich Schwarz bemærker om billedets mangfoldige undertemaer: »Det handler om luftfotografiet som ved siden af den japanske kunsts indtrængen fik en afgørende indflydelse på de impressionistiske maleres nye optiske holdning - fugleperspektivet; det satiriserer over en virkelig person blandt tidlige franske fotografer og hans lidenskab for underholdning; det latterliggør den fotografiske professions hastige opblomstring og rejser $i$ sarkasmens form spørgsmålet om, hvorvidt fotografiet skal betragtes som en kunst eller som en mekanisk procedure. ${ }^{77}$

For nu at runde af vil jeg foreslå, at Daumier's tegning med lidt god vilje også kan fortolkes som et symbol på selve okularcentrismens situation i slutningen af det 19. århundrede. Det ubevægelige blik langt vak fra, som oplysningstiden - med undtagelser som Diderot - kunne identificere med uvildig erkendelse, blev nu rystet af de nye kulturelle vindes kræfter. Nye visuelle erfaringers vide udbredelse ved hjælp af både sociale og tekniske ændringer medførte usikkerhed om den sandhed og illusion, som øjet kunne formidle. Skønt den mest fremherskende etos indtil $1890^{\prime}$ erne stadig var den observationsorienterede tilgang, der kaldes positivisme, med naturalismen som dens korrelat i bogstavelig forstand, blev en ny holdning nu synlig i horisonten. Den Cartesianske perspektivismes hegemoni blev langsomt trevlet op, først med udforskningen af andre synsmåder og endelig af det 20. århundredes fuldt udfoldede kritik af synet i enhver af dets former. Denne kritiks første umiskendelige tegn skimtes $i$ fransk maleris udvikling fra impressionisme til post-impressionisme, i opbygningen af modernismens litterære teori og praksis og i Henri Bergsons nye filosofi. Med disse udviklingsforløb er vi allerede på tærsklen til den fordømmelse af synet, overvågning og efterligning [simulacrum], som er så karakteristisk for nutidig fransk tænkning. Jeg håber, at jeg på en overbevisende måde har demonstreret, at kameraet ganske uventet blev det instrument, der befordrede os ud på den anden side. 
Oversat af: Lise Busk-Jensen efter Martin Jay: »Photo-unrealism: The Contribution of Camera to the Crisis of Ocularcentrism «, et foredrag holdt på Institut for litteraturvidenskab, Københavns universitet i foråret 1989. Martin Jay er professor ved University of California, Berkeley.

\section{Noter}

1. For tidligere diskussioner af aspekter af dette synspunkt, se Martin Jay: »In the Empire of the Gaze: Foucault and the Denigration of Vision in 20thCentury French Thought « in: David Couzens Hoy (ed.): Foucault: A Critical Reader, London 1986. M. Jay: „Scopic Regimes of Modernity، in: Hal Foster (ed.): Visions and Visuality, Port Townsend, Washington 1988. M. Jay: »The Rise of Hermeneutics and the Crisis of Ocularcentrism« in: Poetics Today 9/2, 1988.

2. Hans Jonas: „The Nobility of the Sight« in: The Phenomenon of Life: Toward a Philosophical Biology, Chicago 1982.

3. Se f.eks. Claude Nori: French Photography: From Its Origins to the Present, oversat af Lydia Davis, New York 1979. Gisela Freund: Photography and Society, oversat af Richard Dunn et al., Boston 1989 [org. Photographie et societé, Paris 1974 (omarbejdet disputats fra 1936)]. Beaumont Newhall: The History of Photography: from 1839 to the Present Day, New York 1964; Regards sur la photographie en France au XIXe siècle, 180 chefs'd'oeuvre de la Bibliothèque nationale, Paris 1980.

4. Den ældre Niépce bliver almindeligvis regnet for at være den første, der fastholdt et billede på en tinplade, der var gjort lysfølsom med asfalt. Det lykkedes i 1826, men først da Daguerre og den yngre Niépce forbedrede det i slutningen af 1830 'erne, var det klart til at blive afsløret. Talbot's store indsats bestod i opfindelsen af negativet, som gjorde det muligt at tage mange aftryk af det samme billede.

5. "The Fine Arts: A New Discovery«, optrykt i Beaumont Newhall (ed.): Photography: Essays and Images, New York 1980, p. 17.

6. [Den ældre Niépce: Joseph-Nicéphore Niépce (1765-1833) O.a.]

7. Se litografien fra 1840 med denne overskrift af T.H. Maurisset, optrykt $i$ Freund (se note 3) p.27.

8. For en diskussion af den tidlige forståelse af den nye teknologi $i$ en realistisk kontekst se Victor Burgin: »Introduction« in: V. Burgin (ed.): Thinking Photography, London 1982, p. 10.

9. Se Richard Rudisill: Mirror Image, Albuquerque 1971.

10. Andre Bazin: »The Ontology of the Photographic Image In: What is Cinema?, ed. og oversættelse Hugh Gray, forord af Jean Renoir, Berkeley 1967, p. 13 [org. Qu'est-ce que la cinema I-III, Paris 1958-61]. Bazin udvidede naturligvis også sin realistiske æstetik til at omfatte filmen. 
11. Roland Barthes: Image - Music - Text, oversat af Stephen Heath, New York 1977, p. 17. [Org. i Communications 1, 1961. For en dansk diskussion af Barthes' filmteoretiske positioner se B. Fausing og P. Larsen (red.): Visuel kommunikation, Kbh. 1989(1980) O.a.]

12. [Daguerre opfandt sin diorama i 1822. Det er et billede malet på gennemsigtigt materiale (glas eller lærred), som belyses bagfra, således at forskelligt vejrlig, ildebrande o. lign. illuderes. O.a.]

13. Noël Burch: „Charles Baudelaire versus Doctor Frankenstein« in: Afterimage 8/9, 1981, p. 5. I The World Viewed: Reflections on the Ontology of Film, Cambridge, Mass. 1979, tilføjer Stanley Cavell, at »for så vidt som fotografiet tilfredsstillede et $\emptyset$ nske, så tilfredsstillede det et ønske, der ikke var begrænset til malernes kreds; det var et menneskeligt ønske, der var blevet intensiveret $i$ vesten siden reformationen, om at undgå subjektivitet og metafysisk isolation -et ønske om magt til at nå denne verden efter så længe at have forsøgt, til sidst uden håb, at vise den anden troskab.«, p. 21.

14. [Quattrocento er det italienske 1400-tal. O.a.] For eksempler på denne antagelse, se William M. Ivins, Jr.: Prints and Visual Communication, Cambridge 1985, p. 138, Victor Burgin: »Looking at Photographs« in: Burgin (se note 8) p. 146 og Steve Neale: Cinema and technology: Image, Sound, Colour, London 1985 , p. $20 \mathrm{f}$.

15. Fox Talbot: The Pencil of Nature, London 1844. Ivins (se note 14) kap. VI. Den syntaks, Ivins refererer til, er dobbeltskraveringen eller prikkerne, der bruges til at skabe lys og skygge på traditionelle tryk. For en lignende analyse som understreger realismen i rastede halvtonetryk p̊ fotografier i 1890'ernes massemedier, se Estelle Jussim: Visual Communication and the Graphic Arts: Photographic Technologies in the Nineteenth Century, New York 1974, p. 288.

16. Se fotografen Dauthendeys kommentarer, der er citeret i Walter Benjamin: "A Short History of Photography“ in: Screen, forår 1972, p. 8. [Org. "Kleine Geschicte der Photographie« (1931), på svensk i Bild och Dialektik 1969, citatet s. 49. O.a.]

17. Se brevet til hans mor fra 1865 , hvor han opmuntrer hende til at besøge et atelier, selv om han er bekymret for, at fotografen skal fange alle hendes rynker og fejl. Baudelaire: Correspondance, Paris 1973, vol. 2, p. 554.

18. [Panoramaer var maleriske fremstillinger af landskaber eller bybilleder, der rulledes forbi tilskuerne på brede bånd. O.a.]

19. Aaron Scharf: Ant and Photography, London 1983, p. 34.

20. Dolf Sternberger: Panorama of the 19th Century, oversat af Joachim Neugroschel, Oxford 1977, p. 9.

21. Termen $\gg$ index « blev indført af C.S.Peirce for at angive tegn med direkte eller "motiveret" forbindelse til en referent; han brugte termen "symbol« for at angive dem, der var helt konventionelle og artificielle, $\mathrm{og}$ »kon« for at betyde dem, der lignede deres referent. Se hans "Logic as Semiotic: The Theory of Signs in The Philosophy of Pierce: Selected Writings, J. Buckler (ed.), London 1940, pp. 98-119. Fotografihistorikere har ofte påpeget fotografiets indeksikal- 
ske karakter, f. eks. Rosalind Krauss i »Tracing Nadar«, p. 34, hvor hun argumenterer for, at Nadar var klar over dens betydning. Krauss har udviklet ideen om indeksikalitet for at beskrive også visse former for modernistisk kunst. Se hendes „Notes on the Index, Parts I and II « in: The Originality of the Avantgarde and Other Modemist Myths, Cambridge, Mass. 1985. Pierce så selv fotografiet som en kombination af indeksikalske og ikonografiske træk. Se diskussionen i Mitchell: Iconology, p. 56f.

22. Freund (se note 3) p. 64.

23. Se diskussionen i James Borcoman: "Notes on the Early Use of Combination Printing « in: Van Deren Coke (ed.): One Hundred Years of Photographic History: Essays in Honor of Beamont Newhall, Albuquerque 1975.

24. Citeret i Elisabeth Anne McCauley: A.E.E. Disdéri and the Carte de Visite Portrait Photograph, New Haven 1985, p. 194.

25. Umberto Eco: »Critique of the Image in Burkin (se note 8) p. 34.

26. Joel Snyder: "Picturing vision « in Critical Inquiry VI / 3, 1980, p. 505.

27. James E. Cutting: Perception with an Eye for Motion, Cambridge 1986, p. 167.

28. Craig Owens: »Photography en abyme in October 5, 1978, p. 81.

29. Opfindelsen af stereoskopet kunne f.eks. have en kompliceret effekt på antagelsen af det fotografiske billedes grundlæggende materielle eller indeksikalske natur. For dets tredimensionale effekt var ikke produceret andre steder end $\mathrm{i}$ bevidstheden. Ydermere modarbejdede det, som Jean Claire har bemærket, det permanente billedes fetishkarakter med dets kommercielle muligheder: Fordi det ikke har nogen materiel realitet, tillader det ikke symbolsk udveksling. Som et muligt billede, en immateriel imitation, et helt transparent, alt-for perfekt blændværk af virkeligheden, tillader det ikke én at bytte substansen for dens skygge i modsætning til papirets materielle dokument.« (»Opticeries in October 5, 1978, p. 103). Han fortsætter med at hævde, at Duchamp's anti-nethinde kunst stod i gæld til hans fascination af stereoskopiske billeder og deres efterkommere kendt som anaglyffer.

30. Forbindelsen er foreslået af Anne Hollander i »Moving Pictures« in: Raritan, $\mathrm{V} / 3,1986$, p. 100.

31. Svetlana Alpers: The Art of Describing: Dutch Art in the Seventeenth Century, Chicago 1983, p. 43-44. Se også Carl Chiarenza: »Notes on Aesthetic Relationships between Seventeenth-Century Dutch Painting and Nineteenth-Century Photography in: Coke (se note 23).

32. Fuldstændig lighed mellem objekter og deres bevidsthedsmæssige repræsentation var ikke en antagelse i Descartes' synsmåde. Han insisterede på, at sjælen, ikke øjet, så, og som sådan sørgede den for en naturlig form, der ikke var mekanisk sanset gennem øjets fysiske apparatur. Det var fraværet af denne naturlige form i det fotografiske billede, der hjalp det med at underminere den Cartesianske perspektivisme.

33. Benjamin (se note 16), p. 7.

34. [Muybridge (1830-1904) er kendt for sine serier af øjebliksfotografier af dyr 
og mennesker i bevægelse, optaget fra 1877. I et såkaldt zoopraxiskop kunne billedeserierne, anbragt på roterende skiver, gengive bevægelse, og de blev af betydning for filmens udvikling. O.a.]

35. Scharf (se note 19), p. 211. Thierry de Duve tilføjer, at »med de bevægelige fotografiers fremkomst fandt kunstnere, der var helt opslugt af realismens ideologi, sig selv ude af stand til at udtrykke virkeligheden og samtidig adlyde fotografens domme. For Muybridge's snapshots af en galopperende hest viste, hvordan dyrets bevægelser var, men de formidlede ikke følelsen af disse bevagelser.« (»Time Exposure and Snapshot: The Photography as Paradox« in: October 5, 1978, p. 115.)

36. Den måske mest gennemtrængende udforskning af denne lænke er Roland Barthes: Camera Lucida: Reflections on Photography, oversat af Richard Howard, New York 1981. [På dansk Det lyse kammer, Kbh. 1983, oversat af Karen Nicolajsen. O.a.] Se også Thierry de Duve (se note 35). Som Steve Neale har bemærket, så synes opfindelsen af filmen at give håb om en revitalisering af billedet, en omvending af still-fotografiets rigor mortis. Se hans diskussion i Cinema and Technology (note 14), p. 40.

37. John Berger: Ways of Seeing, London 1972, p. 18. [På dansk: Se på billeder, Kbh. 1984. O.a.].

38. Norman Bryson: Vision and Painting: The Logic of the Gaze, New Haven 1983, kap. 5. Deiksis, anerkendelsen af det tilfældige her og nu i enhver visuel kunst, er, hæuder han, undertrykt i den herskende vestlige billedkunst. Roger Scruton skriver, at hovedforskellen mellem fotografi og malet portræt ligger i det sidstes fors $\emptyset \mathrm{g}$ på at fange en opfattelse af modellen, der er repræsentativ for et længere tidsstræk og ikke kun et øjebliksbillede af ham eller hende. Se hans The Aesthetic Understanding: Essays in the Philosophy of Art and Culture, London 1983, p. 110. I modsæetning til Bryson bruger han argumentet til at benægte fotografiets kunstneriske anseelse; han regner det snarere for et kausalt end for et intentionelt medium.

39. Siegfried Kracauer: „Die Photographie in: Das Omament der Masse: Essays, Frankfurt 1963, p. 35. [På dansk. "Fotografiet« in: Kultur \& Klasse 44, 1982. O.a.]

40. Henri Bergson: Matter and Memory, oversat af N.M. Paul og W.S.Palmer, New York 1988, p. 38. Senere, i Creative Evolution fra 1907 [org. L'évolution créatrice, på dansk i Knud Ferlovs oversættelse fra 1915: Den skabende udvikling. O.a.] introducerede han termen »cinematographic « for at angive den falske følelse af tidslighed, som kombinationen af en strøm af ubevægelige dele med en abstrakt, mekanisk efterligning af tiden skaber.

41. Jean Louis Comolli: »Machines of the Visible«, in. Teresa de Lauretis og Stephen Heath (ed.): The Cinematic Apparatus, New York 1985, p. 123. For en lignende analyse, se Neale (note 14) p. 38.

42. For en analyse af dets betydning, se Krauss (note 21).

43. Den bedste opsummering af debatten findes hos Scharf (se note 19). Se også Paul C. Vitz og Arnold B.Glimcher: Modem Ant and Modem Science: The 
Parallel Analysis of Vision, New York 1984.

44. I en betydningsfuld dom kaldet »Maver og Pierson v. Thiebault, Betbeder og Schwabbe fra 1862 afgjorde den franske ret, at fotografi faktisk er en kunstart for at beskytte copyright'en på billeder. En vægtig undersøgelse af denne doms implikationer findes hos Bernard Edelman i The Ownership af the Image: Elements of a Marxist Therory of Law, oversat af E. Kingdom, London 1979.

45. Citeret og diskuteret i Gabriel Cromer: "L'original de la note du peintre Paul Delaroche à Arago au subject du Daguerreotype in: Bulletin de la Societé Française de Photographie et de Cinématographie, 3. serie, XVII, 1931, p. $114 \mathrm{f}$.

46. Freund (note 3) p.10.

47. Scharf (note 19) pp. 62 og 89.

48. Vitz og Glimcher (note 43) p. 50.

49. Ibid. pp. 118 og 122. Scarf (note 19) p. 255.

50. McCauley (note 24) p.172.

51. Citeret fra en samtale med Emile Bernard i Herschel B. Chipp: Theories of Modern Art: A Source Book by Artists and Critics, Berkeley 1968, p. 13.

52. Citeret i Heinrich Schwarz: Art and Photography: Forerunners and Influences, ed. William E. Parker, Chicago 1987, p. 141.

53. Citeret i ibid. p. 140.

54. Citeret i Freund (note 3) p. 77. Denne bemærkning faldt i 1858 . Kort efter skiftede Lamartine mening efter at have set Antoine Samuel AdamSalomons meget udtryksfulde arbejder.

55. Baudelaire: »Photography« in Newhall (note 5) pp. 112-13.

56. Ibid. p. 113.

57. Ibid. p. 112.

58. I Freund (note 3) p. 88 diskuteres forsøgene på at få fotografier til at ligne alt muligt fra oliemalerier til litografier. Proust's kritiske reaktion på mediet er omtalt hos Susan Sontag: On Photography, New York 1978, p. 164.

59. Schwarz (note 52); Peter Galassi : Before Photography: Painting and the Invention of Photography, New York 1981.

60. Galassi (note 59) p. 25. Rosalind E. Krauss advarer imidlertid imod at godtage Galassi's argumentation, når det drejer sig om stereoskopiske fotografier som f.eks. Timothy O'Sullivans, der var tilstræbt perspektiviske. Se Krauss (note 21) p. $134 \mathrm{f}$.

61. André Malraux: The Voices of Silence, Princeton 1978. [Org. Les voix du silence, 1951. O.a.]

62. Ivins (note 14) p. 147. Det skal måske også anføres, at det kan have en frigørende effekt at blive udsat for billeder af forskellige etniske typer. Således hævder McCauley f.eks., at Lavaters fysiognomiske arbejder åbnede muligheden for, at man også kunne værdsætte skønhed i andre former end dem, som Winckelmanns hellenistiske model havde bemyndiget. Se McCauley (note 24) p. 168.

63. Johannes Fabian: Time and the Other: How anthropology Makes its Object, New 
York 1983. Stephen A. Tyler: "The vision Quest in the West or What the Mind's Eye Sees« in: Joumal of Anthropological Research 40/1, 1984, pp. 2340.

64. For en nylig diskussion af disse tvetydigheder, se James Clifford: The Predicament of Culture: Twentieth-Century Ethnography, Literature and art, Cambridge, Mass. 1988, kap. 9.

65. Sontag (note 58 ) p. 55.

66. McCauley (note 24). Se også Freund (note 3) p. $55 f$.

67. Egalitarismen, som kameraet skabte, kan fortolkes positivt og negativt afhængigt af ens holdning til det samfund, det skildrede. For dem, der understreger samfundets stadig klasseopsplittede struktur, kan fotografiets demokratisering angribes som ideologisk. Et sådant argument kan ses hos Neale (note 14) p. 23. Tilsvarende bekymringer viste sig i ovrigt meget tidligere. En interessant redegørelse for deres skiftende former i en amerikansk kontekst findes hos Neil Harris: „Iconography and Intellectual History: The Half-Tone Effect « in: John Higham og Paul K. Conkin: New Directions in American Intellectual History, Baltimore 1979.

68. John Tagg: The Burden of Representation: Essays on Photographies and Histories, London 1988, p. 76.

69. McCauley (note 24) p. 224.

70. Donald E. English: Political Uses of Photography in the Third French Republic 1871-1914, oversæettelse Ann Arbor, Michigan 1984.

71. Berger (note 37) p. 48f; Sontag (note 58) p. 5; Tagg (note 68) kap. 3.

72. Nori (note 3) p. 21.

73. Se Sander L. Gilman (ed.): The Face of Madness: Hugh W. Diamond and Origins of Psychiatric Photography, New York 1976; Georges Didi-Huberman: Invention de l'hysterie: Charcot et l'iconographique de la Salpêtriére, Paris 1982; Elaine Showalter: The Female Malady: Women, Madness and English Culture, 1830-1980, New York 1985.

74. Om de traditionelle forsøg på at afbilde vanviddet, se redegørelsen i Sander L. Gilman: Seeing the Insane: A Cultural History of Psychiatric Illustration, New York 1982. [Géricault's billeder er emnet for Vagn Lyhnes artikel »Lægerne, maleren og de monomane«, som efterfølger Martin Jay's i dette nummer af $K \& K$. O.a.]

75. En diskussion heraf ses i Stephen Kern: The Culture of Time and Space 18001918, Cambridge, Mass. 1983, p. 116.

76. Blandt mange studier om Nadar, se især Jean Prinet og Antoinette Dilasser: Nadar, Paris 1966; Nigel Gosling: Nadar, London 1976; Philippe Neagu et al.:Nadar, Paris 1970; Roger Greaves: Nadar ou le paradox vital, Paris 1980.

77. Schwarz (note 52) p. 141. 